\title{
GPPS-BJ-2019-163
}

\section{Experimental Research on Rotating Stall Induced Blade Vibration in an Unshrouded Centrifugal Compressor}

\author{
Xinwei Zhao \\ School of mechanical engineering, Dalian \\ university of technology \\ xinweizhao@mail.dlut.edu.cn \\ Dalian, Liaoning Province, China \\ Shuhua Yang \\ Shenyang Blower Works Group \\ yshemail@sina.com \\ Shenyang, Liaoning Province, China
}

\author{
Hongkun Li \\ School of mechanical engineering, Dalian \\ university of technology \\ link@dlut.edu.cn \\ Dalian, Liaoning Province, China \\ Zhenfang Fan \\ School of mechanical engineering, Dalian \\ university of technology \\ 1164222434@qq.com \\ Dalian, Liaoning Province, China
}

\begin{abstract}
In recent years, the problem of forced vibration of centrifugal compressor blades at low mass flow rate has become prominent and gradually attracts more attentions. This paper is aimed to investigate the mechanism behind this complex fluid-structure coupling phenomenon. A lot of experimental work has been carried out on a full-size single stage centrifugal compressor (SSCC) facility to understand the dynamic behavior of the stall cells and how blade vibrates when suffering such aerodynamic loading condition. Through multiple signals from casing-mounted pressure transducers and strain gauges, the rotating stall is characterized and further correlated with the blade vibration. Not only the individual stall mode but also the coexistence and superposition of different stall modes is observed. Each of them causes different non-synchronous vibration phenomena. However, the blade resonance of the tested impeller is not observed currently.
\end{abstract}

\section{INTRODUCTION}

Centrifugal compressors have the advantages of high single-stage pressure ratio, wide working range and compact structure. They are highly valued and applied in important fields such as turbochargers in automotive engines, the processing of natural gas, aerospace and gas turbine engines. However, with increased design rotating speed, higher mass flow rate and pressure ratio, the static aerodynamic loads sustained by the impeller blades becomes much higher. According to the Goodman relation, the fatigue life of impeller will decrease with limited allowable alternating stress. The structural integrity of impeller meets great challenges, especially under off-design conditions like rotating stall. The excitation force becomes much more serious and large vibration amplitude will appear, making compressor blades trend to failure. However, the unstable operating behavior of rotating stall is not yet fully understood. It is still a key aspect of current research in turbomachinery. Investigation efforts is still needed to understand the flow instability of compressors and develop blade health monitoring methods for more reliable operation of the impellers.

Great number of numerical and experimental studies have been conducted to reveal the mechanism of rotating stall in the past few decades (Day, 2015). However, compared to axial compressor which received great attention in the past (Emmons et al., 1955; Greitzer, 1976a; Greitzer, 1976b; Cumptsy and Greitzer, 1982), researches about rotating stall happened in centrifugal compressors started later (Jansen, 1964; Lennemann and Howard, 1970). Early works of Abdelhamid (Abdelhamid, 1980; Abdelhamid, 1981) investigated the effects of vaneless diffusers with different geometries on rotational stall. Rotating stall cells are normally identified as pressure disturbance rotating in the same direction relative to the impeller until Spakovszky first discovered the backward traveling rotating stall wave (Spakovszky, 2004). This finding is meaningful since it gives another possible dynamic propagation characteristic of the rotating stall and also affects the relationship between the blade vibration and rotating stall. Except vaneless diffuser, stall happened in vaned diffusers has also raised great attention nowadays. Fujisawa et al. (Fujisawa et al., 2016; Fujisawa et al., 2018) combined experimental and numerical methods to study the unsteady flow phenomenon of the rotating stall in vaned diffuser. Detailed evolution process of rotating stall both in the impeller and diffuser passages was presented. Wang (Xue et al., 2018) focused on the impact of different vane angles on rotating stall happened in a variable 
vaned diffuser. Results show that the interaction between the impeller and diffuser is the main factor causing the flow instability. With the vane angle increased, high-frequency stall occurs accompanying mild surges initially, and then directly develops into deep surges. Xi et al. (Zhao et al., 2018) conducted detailed experiments to analyse the spike-type rotating stall happened in a 1.5 stages centrifugal compressor. Blade passing irregularity coefficient was further proposed for spike-stall warning. In addition to experiment-based results, different useful models to describe the rotating stall process were also produced (Longley, 1994). However, modern computational fluid dynamics (CFD) are more powerful to show the flow instability zones and how the stall cells propagate after formed in the flow passage. Halawa et al. presented a description of the stall development in two different cases (with vaned and vaneless diffuser) (Halawa et al., 2015). Different flow behavior was discovered in vaned and vaneless diffuser cases. For the vaneless diffuser, stall occurred near the shroud side of the impeller, while for the vaned diffuser, stall occurred near the impeller outlet. Bousquet also numerically investigated the stall inception mechanisms in a centrifugal compressor stage (Trebinjac et al., 2016). This study showed similar stall behavior happened in axial compressor. Furthermore, they also correlated the modal wave rotating in the vaneless space with the stall process and the pressure ratio drop.

Most of these works were concerned about the causes and evolution of the rotating stall in flow passage from an aerodynamic perspective. Rotating stall induced nonsynchronous vibration (NSV) and resonance should be paid more attentions. Sorokes gave a discussion centred on forced vibration of rotors depending on the resulting vibration characteristics including rotating stall (Sorokes et al., 2016). Early works coming from Seidel et al. (Seidel et al., 1991; Hasemann et al., 1991) observed large amplitudes of vibration occurred in centrifugal compressor impeller. Identified 7 stall cells which induced dangerous blade vibration was also found in recent work by Jenny (Jenny and Bidaut, 2016) using the IGV sweep method. Mechanisms behind this complex fluid- mechanical coupling phenomenon should also be interpreted more in detail. In addition to qualitative analysis of rotational stall, it is also urgent to quantitatively characterize its effects on blade vibration.

In this paper, the fluid-structure interaction mechanism of an unshrouded centrifugal impeller under rotating stall operating conditions is experimentally analysed and verified. Different stall states are identified by pressure and strain signal at different operating conditions. The pressure fluctuation caused by rotating stall can be further characterized as a time-space varying load, which is the cause of forced vibration or even resonance of the blade.

\section{ROTATING STALL AND IMPELLER FORCED VIBRATION THEORY}

Figure 1 gives a brief picture of typical rotating stall happened in centrifugal compressor. The pressure loading is distorted circumferentially and can be described as a rotating wave arising and decaying intermittently. Corresponding aerodynamic force can be built up in rotating coordinate system (RCS) and correlated with blade vibration.

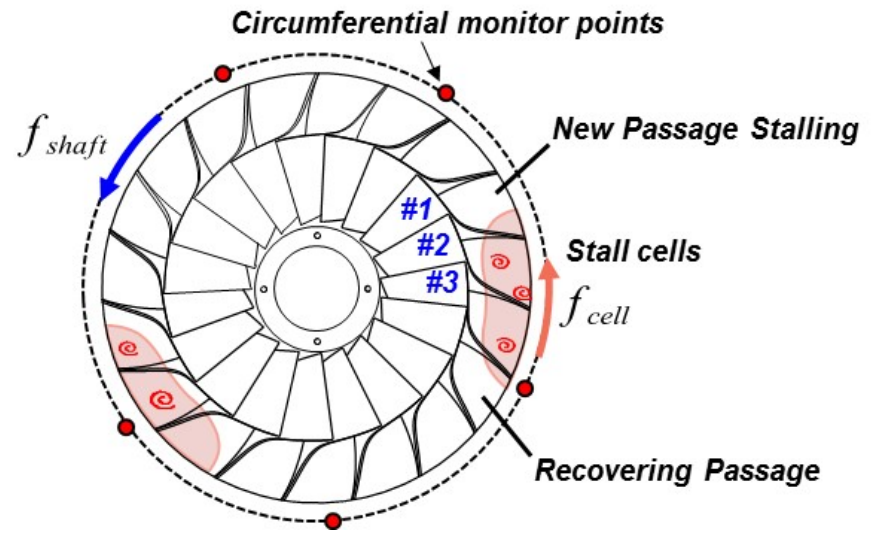

Figure 1 Rotating Stall Model and Induced Blade Forced Vibration

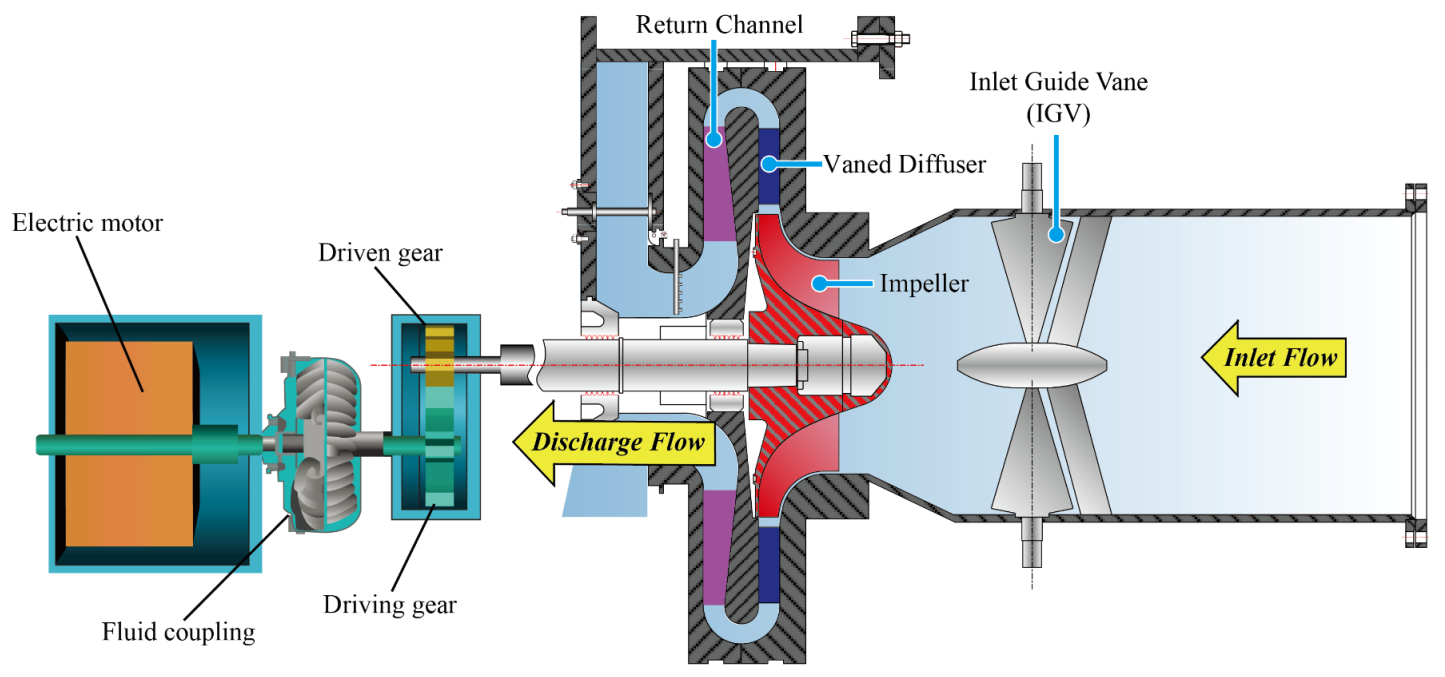

Figure 2 Schematic Representation of the Compressor Test Rig 
The frequency detected by the unsteady pressure sensor on the casing $f_{\mathrm{PC}}$ corresponds to the product of the number of stall cells $\mathrm{NB}_{C}$ and the rotating frequency $f_{\text {cell }}$ of the individual stall cell in stationary coordinates. Relationship between pressure pulsation frequency of rotating stall and blade vibration can be calculated by the following expression:

$$
f_{e}=n \cdot\left[\mathrm{NB}_{C} \frac{\Omega}{60} \pm f_{\mathrm{PC}}\right]=n \cdot \mathrm{NB}_{C}\left(\frac{\Omega}{60} \pm f_{\text {cell }}\right)
$$

Where $n$ is the harmonic index. $f_{e}$ is the frequency of the exciting force.

\section{TEST FACILITIES AND MEASUREMENT PROCEDURE}

The structure of the test compressor is shown in Figure 2. It consists of variable inlet guide vanes (VIGVs), an unshrouded backswept centrifugal impeller, a vaned diffuser and the return channel. The number of blades and main dimensions of compressor test rig is listed in the Table 1. The compressor stage is tested under a large number of operating conditions. Speed ramps and two different constant speeds accompanied by rotating stall flow condition are measured in detail. Different operating points during the experiment are clearly denoted in Figure 3. The black points and lines show the compressor pressure ratio tested for performance purpose while the red and green ones denote the tested operating points in order to show the blade vibration induced by the air flow under different mass flow operating conditions.

During the experiments, strain gauges are used to obtain the impeller vibration response signal. At the same time, the pressure pulsation sensor is arranged in the circumferential direction of the diffuser inlet to obtain the pressure pulsation characteristic frequency under the stall condition. The correlation between the rotational stall pulsation frequency and the impeller vibration response is further verified based on stall parameter identification method. Different test methods and specific details will be described below.

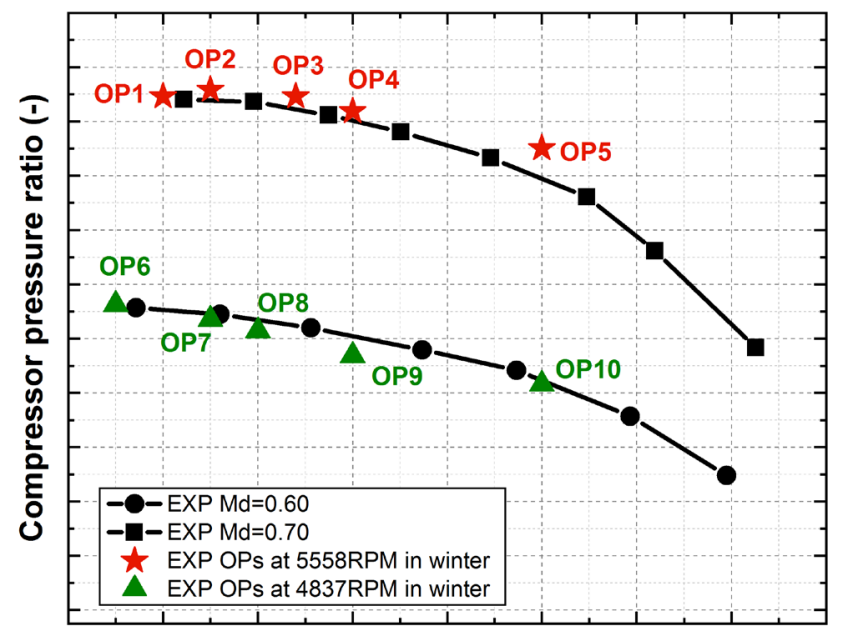

Flow coefficient (-)

Figure 3 Centrifugal Compressor Stage Performance Curve and Tested Operating Points
Table 1 Specifications of the Investigated Compression Stage

\begin{tabular}{cc}
\hline Parameters & Value \\
\hline Number of guide vanes & 11 \\
Number of impeller blades & 19 \\
Number of diffuser vanes & 20 \\
Impeller outlet diameter D2 $(\mathrm{mm})$ & 810 \\
Impeller outlet width b2 $(\mathrm{mm})$ & 57.5 \\
Diffuser inlet diameter D3 $(\mathrm{mm})$ & 900 \\
Diffuser outlet diameter D4 $(\mathrm{mm})$ & 1242 \\
\hline
\end{tabular}

\section{DATA ACQUISITION}

The unsteady static pressure is measured at several locations in flow passage from compressor inlet to diffuser outlet. Figure 4 gives the axial view of these transducer positions. The circumferential pressure pulsation at impellerdiffuser interface (M2) is monitored for 5 points (B1-B5). The angular distribution of these measurement locations is also shown in this figure. These signal data will be mainly used for stall analysis. The sampling rate for the pressure transducers depends on the frequencies of interest. The sampling frequency is set to $20.48 \mathrm{KHz}$ which is sufficient to resolve the blade passing frequency (BPF) and also the rotating stall frequency (RSF).

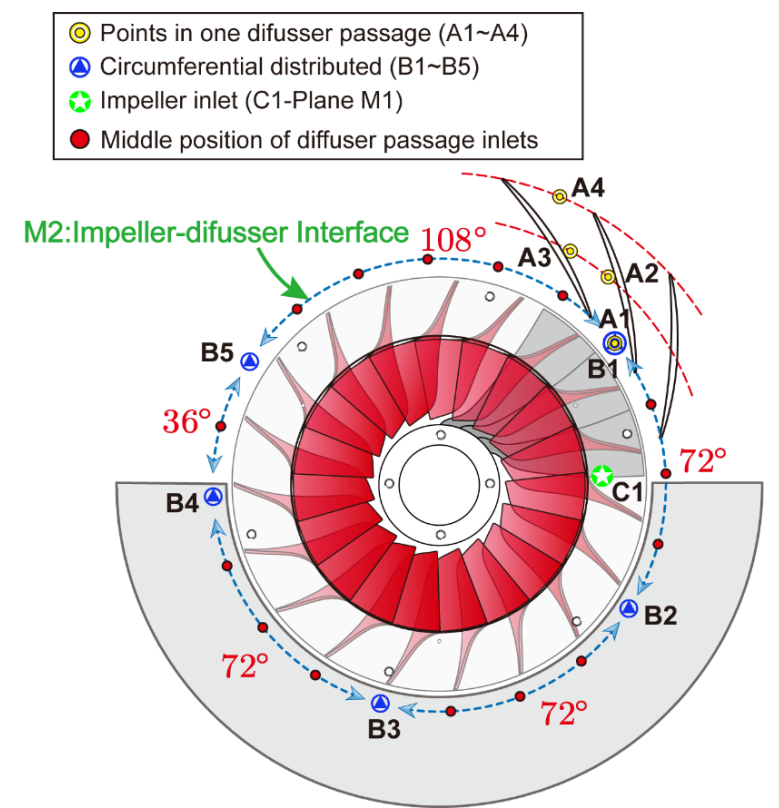

\section{Figure 4 Casing-mounted Pressure Transducer Positions in Axial View}

Centrifugal compressor blade strain test can effectively verify the simulation results and obtain the modal frequency of the tested blades under real operating conditions, which provides a basis for blade vibration analysis and amplitude quantification. In this experiment, 4 strain gauges (Figure 5) in total is installed on the surface of the blade. Compact dynamic data acquisition instrument is installed in the shaft hole of the impeller to continually acquire the signal. The sampling frequency is set to $5 \mathrm{KHz}$. 


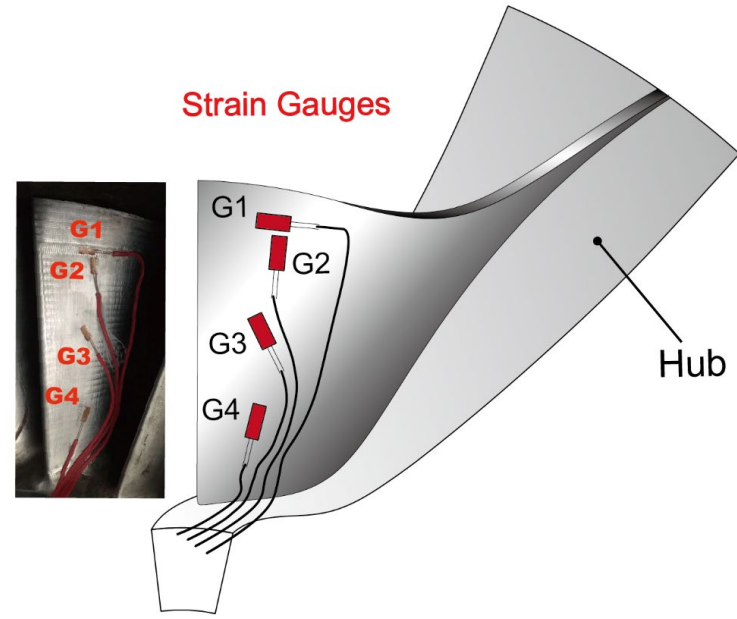

Figure 5 Monitor Points for Strain Gauge Measurement

\section{RESULTS AND DISCUSSION}

\section{Non-synchronous blade vibration phenomenon during speed ramp testing}

Rotating stall induced vibration is first found by the speed ramp testing method. This method first adjusts the compressor to operate at higher speeds and low mass flow rate, and further maintains the mass flow valve setting and continuously changes speed. During the experiment, the impeller is first adjusted to operate at OP2 (Figure 3), and the impeller speed is then decelerated from 5,599 RPM to 3,000 RPM. The strain data under low flow rate condition is collected to study the transient rotating stall induced vibration phenomenon.
Different IGV blade angles and mass flow rate is also tested for comparison. Figure 6 gives one of the testing results and shows the time-frequency spectrum of strain gauge G3 (Figure 5). Two different non-synchronous blade vibration are observed here.

Figure 6 (a) shows the strain time-domain signal. It can be seen that the strain response is larger at higher speeds. As the speed decreases, the static part of strain signal gradually decreases and dynamic response caused by pressure pulsation decreases as well. In Figure 6 (b), two NSV regions are clearly denoted in the time-frequency space which corresponds to a five stall cells mode and an eleven stall cells mode respectively. The 5-stall cells mode is also observed in the following quasi-steady operating condition. The variable speed testing method gives us a quick way to view the rotating stall induced vibration information. However, the operation is transient and unstable. It is not suitable for parameter identification and vibration quantification. Experiments conducted under quasi-steady condition is still needed.

\section{Dynamic characteristics of stall propagation based on parameter identification method}

In order to characterize the stall cell pattern during different quasi-steady operating conditions, the FFT spectrum combined with circumferential pressure distribution is used for identification of the stall parameters since it is the most used and reliable method for industrial application. The propagating direction can be determined by signals coming from two closely spaced probes. However, the direction is still difficult to be clearly interpreted under certain circumstances. Thus, the relationship between pressure pulsation and blade vibration provided by equation (1) is further adopted to give a reliable assessment. Here, OP2 in Figure 3 is first analysed in detail to extract the rotating stall parameters, including stall cell numbers and rotating speed. (a)

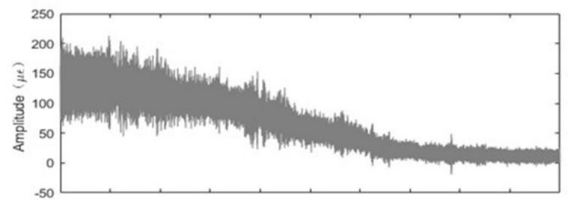

(b)

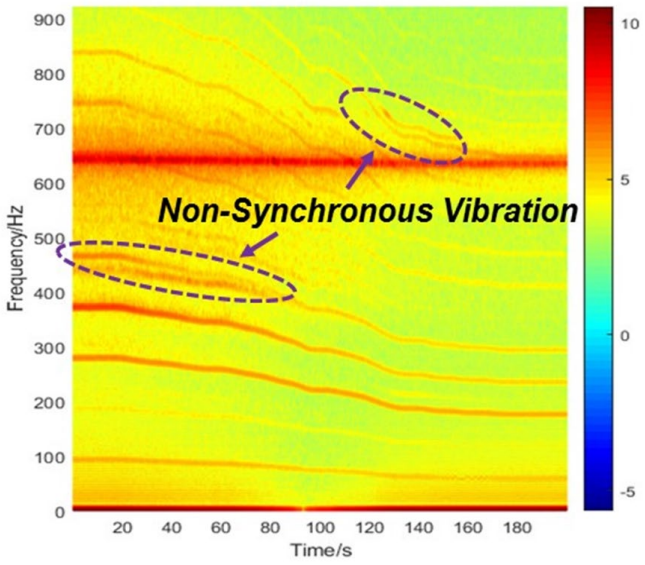

Figure 6 Spectrogram of Strain Gauge G3 during Speed Ramp (a)

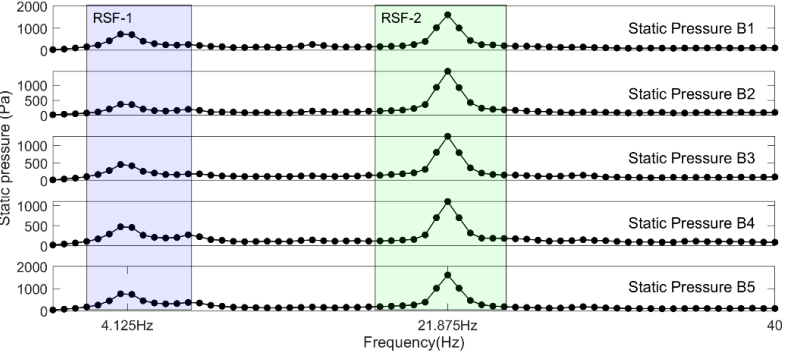

(b)
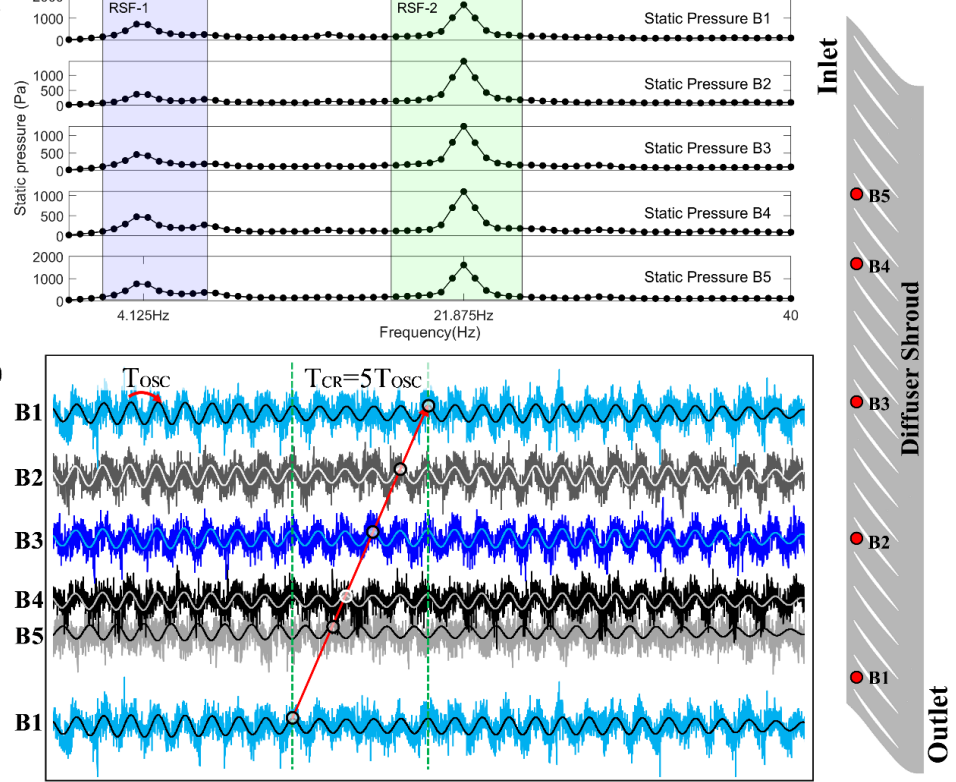

Figure 7 Pressure Transducer Time Signals in Circumferential Direction 
Figure 7 (a) gives the spectrum of the pressure signal. The most obvious characteristic frequency of the rotating stall measured in stationary coordinate is $f_{\mathrm{PC}}^{R S F_{2}}=21.875 \mathrm{~Hz}$. However, in a certain period of time, another low frequency $f_{\mathrm{PC}}^{R S F_{1}}=4.125 \mathrm{~Hz}$ will also become quite dominant. This phenomenon corresponds to the coexistence of different stall modes, which cannot be easily fond from pressure sensors distributed in the circumferential direction. However, it can be verified by the induced blade vibration response.

Firstly, the five stall cells mode is identified and parameters is also established. In Figure 7 (b), a graphical matter based on band pass filtered pressure traces is further used to acquire the stall parameters. Within the graph, pressure signals are plotted from bottom to top according to their circumferential positions in the direction of impeller rotation. In order to form one revolution, the pressure signal of the first sensor is plotted once more.

During the period of rotating stall stably formed, it can be found that the circumferential 5-channel band-pass filtered pressure signal is almost the same phase at any time, but the fourth channel is in the inverted state. According to the sensor distribution angles, this phenomenon indicates that $36^{\circ}$ corresponds to half of the distance between two adjacent stalls in a cylindrical coordinate system along the direction of propagation. The identified stall mode is a stall group consisting of five cells. If the peak of $\mathrm{B} 1-0^{\circ}$ is connected with the corresponding one of $\mathrm{B} 5-108^{\circ}$, which is delayed one and a half cycle, and extend to $\mathrm{P} 1-360^{\circ}$, the stall propagation trajectory which crosses all signal peak positions is extracted. The fluctuation period $T_{\text {OSC }}$ corresponds to the low frequency of the pressure pulsation induced by every stall cell while $T_{C R}$ is the overall period induced by the whole stall group. The relationship between $T_{O S C}$ and $T_{C R}$ is $T_{C R}=5 T_{O S C}$ for this five stall cells mode. And the rotating speed of each stall cell is $f_{\text {cell }}=21.875 / 5=4.375 \mathrm{~Hz}$.

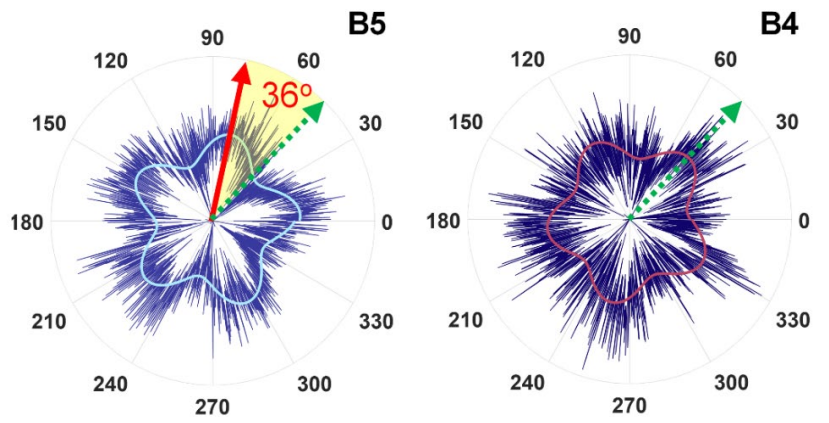

Figure 8 Polar coordinate representation of five stall cells induced pressure distribution

The amplitudes of the five stable stalls are similar in the circumferential direction to form distributed low-speed flow zone, corresponding to a 5-cycle pressure distribution. It is also not static but moving in the circumferential direction as a whole. The five stall cells distorted pressure distribution can be plotted in the polar coordinate system, as Figure 8 shows. It is the origin of the blade non-synchronous vibration occurring under rotating stall dominated aerodynamic loading condition.

The propagation direction is further established combining blade vibration information. Figure 9 gives the corresponding blade vibration spectrum. Before the compressor test rig operates at OP2, a surge happened during the mass flow adjustment which needs to be explained. It has been denoted and shown in Figure 9. And then, the mass flow rate is readjusted to OP2. During the rotating stall period, the five stall cells mode induced blade vibration is first fond. The engine order of the vibration is 4.77. It is not an integer of the shaft rotating passing frequency which means nonsynchronous vibration happened during rotating stall operating condition. Based on the identified parameters and equation (1), the relationship can be verified:

$$
\left\{\begin{array}{l}
f_{e}^{\text {Strain }}=4.773 \cdot f_{r}=446.3 \mathrm{~Hz} \\
f_{e}^{\text {scell }}=\mathrm{NB}_{C} \cdot f_{r}-f_{\mathrm{PC}}^{R S F_{2}}=445.625 \mathrm{~Hz} \\
f_{r}=93.5 \mathrm{~Hz}
\end{array}\right.
$$

So, it has $f_{e}^{\text {Strain }} \approx f_{e}^{5 \text { cell }}$, where $f_{e}^{\text {Strain }}$ is the vibration frequency exciting in the blade response signal, $f_{e}^{5 \text { cell }}$ is the virtual blade vibration frequency calculated by rotating stall parameters and equation (1). As can be seen, these two frequencies agree quite well. There is only a small difference (less than $1 \mathrm{~Hz}$ ) between $f_{e}^{\text {Strain }}$ and $f_{e}^{\text {scell }}$ due to numerical error or spectral resolution.
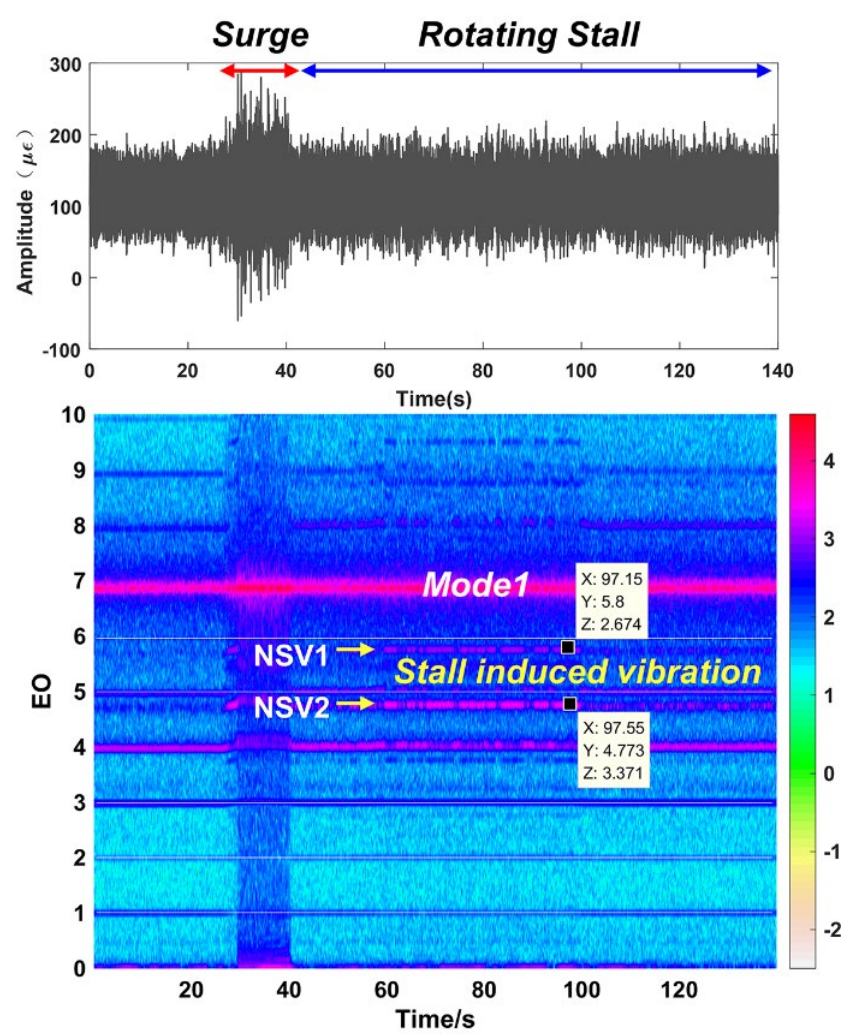

Figure 9 Spectrogram of Strain Gauge G3 at OP2

And the propagation direction is the same as the impeller rotation since " - " is used in equation (2) instead of " + ". It can be found through simple analysis. In RCS, impeller 
structure is static while the force is rotating around it. If the stall group rotates in the same direction, the impeller must rotate more in order to form a periodic load (Stall cells also move a certain distance in the same direction during the impeller rotation). It means the frequency should be smaller than the corresponding integer engine order whose number equals to the stall cell number $\mathrm{NB}_{C}$.

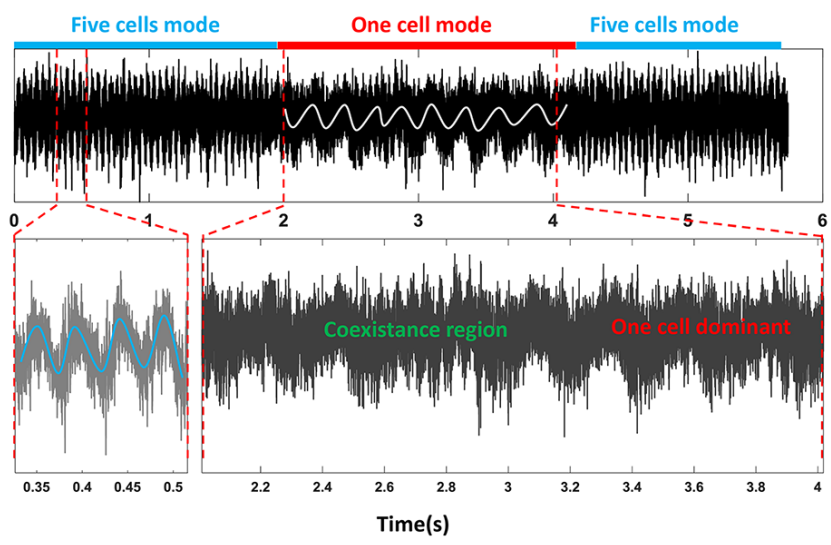

\section{Figure 10 Identified Five Stall Cells Mode Coexists with Another Larger Stall Cell}

However, there also exists another non-synchronous vibration above the identified one whose engine order is 5.8. This phenomenon correlates with the coexistence of different stall modes mentioned above. The frequency $f_{\mathrm{PC}}^{R S F_{1}}=4.125 \mathrm{~Hz}$ corresponds to an individual stall cell whose rotating frequency is near the identified $f_{\text {cell }}^{5 \text { cell }}=4.375 \mathrm{~Hz}$. This individual stall cell is dominant at some time and also will coexist with the 5 stall cells mode. Figure 10 gives the coexisting phenomenon during the stable operation of the compressor test rig at OP2. One large stall cell induced disturbance is further superimposed by the five cells mode induced pressure fluctuation. The vibration frequency corresponding to this superposition phenomenon can be calculated as:

$$
\begin{aligned}
& f_{e}^{\text {Strain }}=5.8 \cdot f_{r}=542.3 \mathrm{~Hz} \\
& f_{e}^{5+1}=(5+1) * 93.5-f_{\mathrm{PC}}^{R S F_{2}}+f_{\mathrm{PC}}^{R S F_{1}}=543.25 \mathrm{~Hz}
\end{aligned}
$$

This one larger stall cell induced frequency $f_{\mathrm{PC}}^{R S F_{1}}$ corresponds to reverse rotation disturbance (" +" is used for $f_{\mathrm{PC}}^{R S F_{1}}$ in equation (3)). The propagation direction is different for these two stall modes.

For the detected 5 cells dominated rotating stall mode, the excitation frequency is about $446 \mathrm{~Hz}$. Although the " $5+1$ " mode frequency is higher than 5 cells mode, it is still lower than the first bending mode of impeller blade. It will not cause a resonant response of the blade for the tested impeller. The rotating stall cell number directly decides the number of orders of the rotating passing frequency and the propagation direction and speed makes it shifted upward or downward. Only large cell number rotating stall mode or the higher harmonics will cause blade resonance which is not observed currently in this compressor test rig. The rotating stall cell number is the core parameter which affects the occurrence of blade resonance.

\section{CONCLUSIONS}

Rotating stall induced blade non-synchronous vibration is experimentally investigated and analysed in a typical industrial single-stage centrifugal compressor. Stall cells are detected and characterized by combining pressure pulsation (PP) and blade response signal, which comes from the fluidstructure interaction measurement work developed over the years. Different findings can be concluded as follows:

(1) Two different non-synchronous blade vibrations are first observed during speed ramp testing. The 5 stall cells pattern is further identified by pressure sensors in circumferential direction. However, the exciting frequency near EO11 is still unknown. The 11 stall cells mode has a quite large cell number.

(2) The 5 stall cells mode finally induces a $446 \mathrm{~Hz}$ blade forced vibration. It is verified by rotating stall theory. Since it is lower than the first bending mode of impeller blade, it does not cause a resonant response of the blade for the tested impeller.

(3) " $5+1$ " rotating stall mode is also observed. One individual stall cell mode becomes dominant at some time and also will coexist with the 5 stall cells mode. It induces a 542 $\mathrm{Hz}$ forced vibration of the impeller.

(4) The blade resonance of the tested impeller is not observed currently in this compressor test rig. It is a reliable design and further investigations are still needed to know more about the rotating stall behavior and even predict and control the stall evolution.

\section{ACKNOWLEDGMENTS}

The work was supported by the Natural Science Foundation of China under Grant No. 51575075 and U1808214 are gratefully acknowledged.

\section{REFERENCES}

Abdelhamid, A. N. (1980). Analysis of Rotating Stall in Vaneless Diffusers of Centrifugal Compressors, in Volume 1B: General. ASME, p. V01BT02A089. doi: 10.1115/80-GT184.

Abdelhamid, A. N. (1981). Effects of Vaneiess Diffuser Geometry on Flow Instability in Centrifugal Compression Systems, in Volume 1: Aircraft Engine; Marine; Turbomachinery; Microturbines and Small Turbomachinery. ASME, p. V001T03A008. doi: 10.1115/81-GT-10.

Cumptsy, N. A. and Greitzer, E. M. (1982). A Simple Model for Compressor Stall Cell Propagation, Journal of Engineering for Power, 104(1), pp. 170-176. doi: 10.1115/81GT-73.

Day, I. J. (2015). Stall, Surge, and 75 Years of Research, Journal of Turbomachinery, 138(1), p. 011001. doi: 10.1115/1.4031473.

Emmons, H. W., Pearson, C. E. and Grant, H. P. (1955). Compressor Surge and Stall Propagation, ASME Transactions.

Fujisawa, N., Hara, S. and Ohta, Y. (2016). Unsteady behavior of leading-edge vortex and diffuser stall in a centrifugal compressor with vaned diffuser, Journal of 
Thermal Science, 25(1), pp. 13-21. doi: 10.1007/s11630-0160829-z.

Fujisawa, N., Inui, T. and Ohta, Y. (2018). Evolution Process of Diffuser Stall in a Centrifugal Compressor With Vaned Diffuser, Journal of Turbomachinery, 141(4), p. 041009. doi: 10.1115/1.4042249.

Gravdahl, J. T. and Egeland, O. (1999). Compressor Surge and Stall: An Introduction, in ASME Transactions, pp. 1-62. doi: 10.1007/978-1-4471-0827-6_1.

Greitzer, E. M. (1976a). Surge and Rotating Stall in Axial Flow Compressors-Part I: Theoretical Compression System Model, Journal of Engineering for Power, 98(2), p. 190. doi: 10.1115/1.3446138.

Greitzer, E. M. (1976b). Surge and Rotating Stall in Axial Flow Compressors-Part II: Experimental Results and Comparison With Theory, Journal of Engineering for Power, 98(2), p. 199. doi: 10.1115/1.3446139.

Halawa, T., Alqaradawi, M., Gadala, M. S., Shahin, I. and Badr, O. (2015). Numerical investigation of rotating stall in centrifugal compressor with vaned and vaneless diffuser, Journal of Thermal Science, 24(4), pp. 323-333. doi: 10.1007/s11630-015-0791-1.

Hasemann, H., Haupt, U., Jin, D., Seidel, U., Chen, J. and Rautenberg, M. (1991). Rotating Stall Flow and Dangerous Blade Excitation of Centrifugal Compressor Impeller: Part 2 - Case Study of Blade Failure, in Volume 1: Turbomachinery. ASME, p. V001T01A045. doi: 10.1115/91GT-103.

Jansen, W. (1964). Rotating Stall in a Radial Vaneless Diffuser, Journal of Basic Engineering, 86(4), p. 750. doi: 10.1115/1.3655945.

Jenny, P. and Bidaut, Y. (2016). Experimental Determination of Mechanical Stress Induced by Rotating Stall in Unshrouded Impellers of Centrifugal Compressors, Journal of Turbomachinery, 139(3), p. 031011. doi: $10.1115 / 1.4034984$.
Lennemann, E. and Howard, J. H. G. (1970). Unsteady Flow Phenomena in Rotating Centrifugal Impeller Passages, Journal of Engineering for Power, 92(1), p. 65. doi: 10.1115/1.3445302.

Longley, J. P. (1994). A Review of Nonsteady Flow Models for Compressor Stability, Journal of Turbomachinery. ASME, 116(2), pp. 202-215. doi: 10.1115/1.2928354.

Seidel, U., Chen, J., Haupt, U., Hasemann, H., Jin, D. and Rautenberg, M. (1991). Rotating Stall Flow and Dangerous Blade Excitation of Centrifugal Compressor Impeller: Part 1 - Phenomenon of Large-Number Stall Cells, in Volume 1: Turbomachinery. ASME, p. V001T01 A044. doi: 10.1115/91GT-102.

Sorokes, J. M., Marshall, D. F. and Kuzdzal, M. J. (2016). A Review of Aerodynamically Induced Forces Acting on Centrifugal Compressors, and Resulting Vibration Characteristics of Rotors, Proceedings of the 45th Turbomachinery \& 32nd Pump Symposia, pp. 1-23. doi: 10.21423/R16K5W.

Spakovszky, Z. S. (2004). Backward Traveling Rotating Stall Waves in Centrifugal Compressors, Journal of Turbomachinery, 126(1), p. 1. doi: 10.1115/1.1643382.

Trebinjac, I., Carbonneau, X., Bousquet, Y., Dufour, G., Binder, N. and Roumeas, M. (2016). Numerical Simulation of Stall Inception Mechanisms in a Centrifugal Compressor With Vaned Diffuser, Journal of Turbomachinery, 138(12), p. 121005. doi: 10.1115/1.4033704.

XUE, X., WANG, T., ZHANG, T. and YANG, B. (2018). Mechanism of stall and surge in a centrifugal compressor with a variable vaned diffuser, Chinese Journal of Aeronautics. Chinese Society of Aeronautics and Astronautics, 31(6), pp. 1222-1231. doi: 10.1016/j.cja.2018.04.003.

Zhao, J. Y., Xi, G., Wang, Z. H. and Zhao, Y. (2018). Investigation of the spike-stall warning method using the blade passing signal, Science China Technological Sciences, 61(6), pp. 830-842. doi: 10.1007/s11431-017-9232-5. 